\title{
Your duty of care to patients experiencing domestic abuse
}

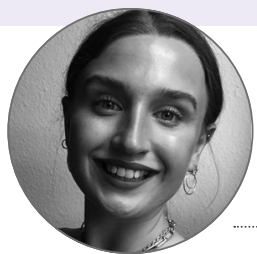

Georgia Halkett

Dundee Dental School

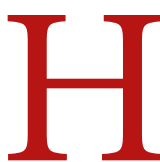

ealth Scotland describes gender based violence, otherwise known as GBV, as 'A major public health, equality and human rights issue. It covers a spectrum of violence and abuse, committed primarily but not exclusively against women by men.' Domestic abuse is a form of GBV perpetrated by a partner or ex-partner and can include physical, sexual, mental and emotional abuse. It is characterised by a pattern of coercive control, which often escalates in frequency and severity over time. ${ }^{1}$

In $2017 / 18$ the police recorded 59,541 incidents of domestic abuse in Scotland. In $81 \%$ of these cases the recorded victim was female and the perpetrator was male. ${ }^{2}$ These figures show that women are disproportionally affected by domestic abuse, in fact, $52 \%$ of women murdered in Scotland were killed by their partner or an ex-partner. ${ }^{3}$ This shockingly high statistic is higher than the global average (38\%). ${ }^{4}$ However, the cause of this may be due to a higher level of reporting of domestic abuse in Scotland. Although this is positive that reporting may be more accurate in Scotland we still have a lot of work to do to support survivors disclosing their experiences of abuse.

The statistics these studies have highlighted show that domestic abuse is a very real problem in our society. As dental students and into our careers, we will encounter victims of domestic abuse. It is within our duty of care to our patients to be educated on the reality of domestic abuse and support those experiencing it where we can. While it is understood that women are the main victim of GBV, it is important to note than men, and the LGBT+ community also experience GBV. A UK study found that $38 \%$ of LGBT+ people had experienced domestic abuse. ${ }^{5}$

A Scottish study found that $80 \%$ of transgender people reported abuse from a partner or ex partner, yet the majority had not received support around this. ${ }^{6}$

GBV does not affect all victims equally; factors such as age, poverty, economic dependence, disability, homelessness and insecure immigration status can heighten people's vulnerability to abuse. It is important to understand that those experiencing domestic abuse face different barriers when seeking help for the situation. Women of ethnic minority may face language barriers in accessing UK services. Disabled women may experience communication or physical barriers to getting help or leaving an abuser, or may be isolated because of their impairment. Signs of domestic abuse may also be overlooked and attributed to their impairment. LGBT+ victims might also have concerns about encountering homophobic attitudes in services and be reluctant to seek support. Young women are at a higher risk of all forms of abuse yet often this can be overlooked or minimised, particularly in their teenage years, with $29 \%$ of women in the UK having experienced physical and/or sexual violence by a current and/or previous partner since the age of $15 .{ }^{1}$

The continuation of violence against women, despite protests, sustained campaigning and a significant online presence, such as the \#MeToo movement, is due to the long history of inequalities between men and women. Oppression of women by men for control and power is often facilitated by violence. These acts of violence are often intensified during times of social breakdown, crisis or conflict. ${ }^{7}$ Since lockdown in March 2020 the National Domestic Abuse Hotline saw a $25 \%$ increase in calls. ${ }^{8}$ As a part of the dental profession we are very aware of the aftermath of coronavirus and the changes it has brought. Domestic abuse has increased and so have the chances of us seeing a patient experiencing it. Awareness of this, and knowing how to respond, will increase your confidence in dealing with disclosures and providing support to your patients.

You might be thinking, what can I do?

From dental students to ready to retire and everyone in between, we are aware of our duty of care to patients, and this must actively incorporate those affected by domestic abuse. Evidence shows the impact we can have simply by asking patients about their situation and supporting them by recording their experiences. Many people, in the health care profession or not, worry about what to say in these cases. NICE have produced guidelines with the following advice: 'If a case of domestic abuse is suspected, asking whether someone has experienced specific acts of violence over a defined period of time is more effective at identifying abuse than simply asking whether or not someone is being abused... and promotion of screening can have a positive impact on identification and onward referral.' ${ }^{9}$

It's important to know that disclosing abuse can be incredibly difficult for those experiencing it, and requires a huge amount of courage to do so. Many people will disclose this information only once, so it is imperative that we respond in a way that is validating, supportive and non-judgemental. 


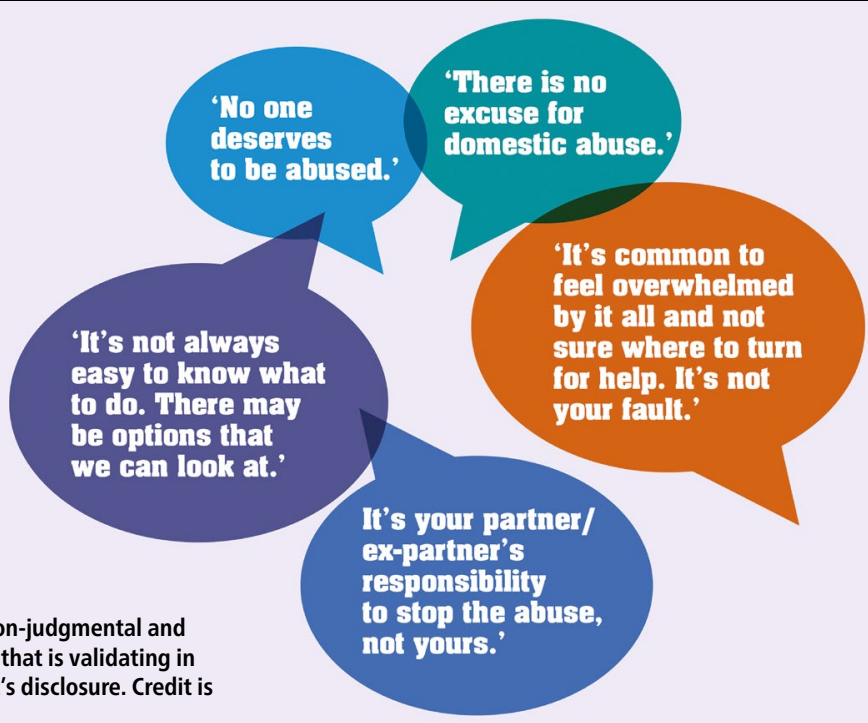

\section{Where you can refer those experiencing domestic abuse}

Scottish Domestic Abuse and Forced Marriage Helpline - 08000271234

Rape Crisis Scotland helpline - 0808801 0302

National LGBT+ Domestic Abuse Helpline - 08009995428

Fig. 1 Examples of non-judgmental and supportive language that is validating in response to a patient's disclosure. Credit is NHS Health Scotland
ASSIST and Police Scotland's Domestic Abuse Task Force
Health Scotland has produced a guide for health care workers detailing how to identify, respond and support those experiencing domestic abuse. It provides useful and recommend guidelines for those working in a variety of health care fields as shown in Figure 1.

Summarised below are three points in dealing with a disclosure:

$\rightarrow$ Identify - Be aware that domestic abuse is a possibility. Recognise signs, create an environment to support disclosure and ask sensitively

$\rightarrow$ Respond - Listen to what they say, show empathy, be non-judgemental, validate their experience and ask what they need

$\rightarrow$ Support - Assess risk and enhance safety, provide information and help them connect to support services.

As domestic abuse encompasses a range of abuse as well as physical, the signs are not always clinically obvious. Other signs to be aware of include:

$\rightarrow$ Attending with their partner who insists on being present

$\rightarrow$ Missed appointments

$\rightarrow$ A delay between the trauma occurring and coming in for treatment

$\rightarrow$ A withdrawn patient who is hesitant to answer your questions

$\rightarrow$ An explanation of the trauma that does not match the clinical presentation. ${ }^{1}$

Despite disclosure of domestic abuse many victims do not leave the perpetrator for a range of complex reasons and it is not our role to persuade them to do so. As dental professionals we understand the importance of record keeping. In some cases, the best you can do to support someone experiencing domestic abuse is record the disclosure. Health Scotland has provided guidance on key points to conclude in your notes.

What to record:

$\rightarrow$ The nature of abuse and, if physical, the type of injuries and symptoms

$\rightarrow$ Details of the disclosure as an allegation not fact

$\rightarrow$ What the victim says and not what you think, but note if you have any concerns

$\rightarrow$ Missed appointments and unanswered telephone calls

$\rightarrow$ The outcome of risk assessment, detailing any concerns, including those relating to children

$\rightarrow$ Action taken

$\rightarrow$ Whether the information is being shared with other agencies.

Permission from the patient is not required to record disclosures of domestic abuse. In the UK, domestic abuse legislation looks at domestic abuse over a period of time. ${ }^{1}$ Explaining to the patient that record keeping is important health information that will help in any future legal proceedings can help patients feel supported in their disclosure.

Just as safeguarding children when you suspect neglect or abuse is recognised as a key aspect of training, so should the safety of women and those experiencing domestic abuse. This is a major public health issue that should be addressed. We are the next generation of health care workers and possibility for change and improvements in handling domestic abuse disclosures lies with us. Many people fear being intrusive when faced with a suspected case of domestic abuse, however research shows that people find it acceptable to be asked about their experiences of domestic abuse. ${ }^{1}$ Health
Scotland advises, 'Your actions would rarely make things worse. If you intervene sensitively and appropriately you could improve the long-term health and wellbeing of the victim and any children involved.' ${ }^{\prime}$.

\section{References}

1. Health Scotland. Gender based violence - What health workers need to know. NHS; 2009.

2. Crime and Justice. Domestic abuse: statistics recorded by the police in Scotland - 2017/18. Scottish Government; 2018.

3. NHS Health Scotland. A brief guide to intimate partner violence and abuse. Edinburgh: NHS Health Scotland; 2021 p. 5.

4. Gender-Based Violence (Violence Against Women and Girls) [Internet]. World Bank. 2019 June 2021. Available from: www.worldbank.org/en/ topic/socialsustainability/brief/violence-againstwomen-and-girls (Accessed September 2021).

5. Donovan C, Hester M, Holmes J, McCarry M. Comparing Domestic Abuse in Same Sex and Heterosexual Relationships. 2006. Available from: https://equation.org.uk/wp-content/ uploads/2012/12/Comparing-Domestic-Abusein-Same-Sex-and-Heterosexual-relationships.pdf (Accessed September 2021).

6. Roch A, Morton J, Ritchie G. Out of sight, out of mind? Transgender people's experiences of domestic abuse. LGBT Youth Scotland and The Scottish Transgender Alliance: Edinburgh; 2010. Available from: www.scottishtrans.org/ wp-content/uploads/2013/03/trans_domestic_ abuse.pdf (Accessed September 2021).

7. Key facts about VAWG | FORWARD. June 2021 Available from: www.forwarduk.org.uk/violenceagainst-women-and-girls/key-facts-about-vawg/ (Accessed September 2021).

8. Kelly J, Morgan T. Coronavirus: Domestic abuse calls up $25 \%$ since lockdown, charity says [Internet]. BBC News. 2020. Available from: www.bbc.com/news/ uk-52157620 (Accessed September 2021).

9. National Institute for Health and Care Excellence, British Columbia Centre of Excellence for Women's Health. Review of Interventions to Identify, Prevent, Reduce and Respond to Domestic Violence. London: National Institute for Health and Care Excellence; 2013. Available from: www.nice.org.uk/guidance/ph50/ evidence (Accessed September 2021).

https://doi.org/10.1038/s41404-021-0906-1 